\title{
Adhesion of melanoma cells to the surfaces of microspheres studied by atomic force microscopy.
}

\section{$\operatorname{AUTHOR}(\mathrm{S}):$}

Shinto, Hiroyuki; Aso, Yuki; Fukasawa, Tomonori; Higashitani, Ko

\section{CITATION:}

Shinto, Hiroyuki ...[et al]. Adhesion of melanoma cells to the surfaces of microspheres studied by ato mic force microscopy.. Colloids and surfaces. B, Biointerfaces 2012, 91: 114121

ISSUE DATE:

2012-03-01

URL:

http://hdl.handle.net/2433/152876

\section{RIGHT:}

C 2011 Elsevier B.V.; この論文は出版社版でありません。引用の際には 出版社版をご確認ご利用ください。; This is not the published version. Please cite only the published version. 


\title{
Adhesion of melanoma cells to the surfaces of microspheres studied by atomic force microscopy
}

\author{
Hiroyuki Shinto,* Yuki Aso, Tomonori Fukasawa, and Ko Higashitani
}

Department of Chemical Engineering, Kyoto University, Katsura Campus, Nishikyo-ku, Kyoto 615-

$$
\text { 8510, Japan }
$$

Phone: +81-75-383-2671, Fax: +81-75-383-2651, e-mail: shinto@ cheme.kyoto-u.ac.jp 


\section{Abstract}

It is of fundamental importance to understand the mechanism of adhesion between a mammalian cell and a material surface. In the present study, we have used atomic force microscopy (AFM) to measure the interaction forces between the murine melanoma cells and the single polystyrene microspheres of different surface chemistries in serum-free culture media: the unmodified hydrophobic polystyrene (bare/PS) and the carboxyl-modified polystyrene (COOH/PS). The cell-microsphere interaction forces have been also measured in the culture media containing the free Arg-Gly-Asp (RGD) peptides as an integrin inhibitor. In the absence of free RGD peptides, the adhesion force for COOH/PS was larger than that for bare/PS. The adhesion force for $\mathrm{COOH} / \mathrm{PS}$ decreased with increasing the concentration of free RGD peptides added in the culture media and then became almost constant at the RGD concentrations larger than $0.5 \mathrm{mg} / \mathrm{mL}$, whereas that for bare/PS remained very small regardless of the RGD concentration. In addition, the effects of the microsphere diameter and the contact time on the adhesion forces were investigated. On the basis of the AFM results, possible mechanism of cell-microsphere adhesion will be discussed.

Keywords:

Atomic force microscopy; Cell adhesion; Integrin; Integrin inhibitor; Melanoma cells. 


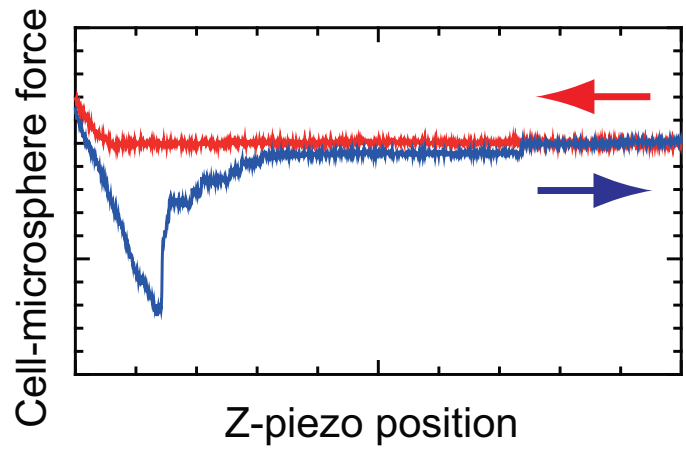




\section{Introduction}

Adhesion of mammalian cells to various substrata, such as extracellular matrix (ECM) and other artificial materials, plays a fundamental role in many processes within multicellular organisms. These processes include the formation and the cohesion of tissues, cell differentiation, cell motility, and pathologies such as cancer proliferation and metastasis. An understanding of the nature of the cell adhesion is of fundamental importance in a wide field of biotechnological and biomedical applications, including bioreactors, tissue engineering, biomaterials, and drug delivery system.

In order to understand the mechanism of adhesion between a mammalian cell and a material surface, we often need to consider the presence of proteins adsorbed on the material surface; especially, the component proteins of ECM such as fibronectin, vitronectin, and laminin play a crucial role in the cell-material adhesion [1]. The integrins are transmembrane adhesion molecules and act as celladhesion receptors that form contacts with ECM. They interact with one of many ECM components, often by recognizing the tripeptide arginine-glycine-aspartic acid (Arg-Gly-Asp or RGD in single-letter amino acid code) therein [2]. In the culture media including ECM proteins, the mammalian cells interact with material surfaces via the ECM proteins adsorbed thereon, where the integrins in cell membranes bind to the RGD sequences of the ECM proteins [3, 4]. Indeed, in cell culture systems, serum including ECM proteins is usually added to culture media, helping anchorage-dependent cells adhere to the surfaces of culture dishes [5].

Atomic force microscopy (AFM) is a good tool to measure the interaction forces of a living cell with a substrate and has been widely employed for cell adhesion studies [6]. To the best of our knowledge, Thie et al. [7] are the first to report the AFM study of the interaction forces between a living mammalian cell and a substrate. Since then, lots of research groups have reported the AFM studies of cell adhesion. Their main focus is on measuring and interpreting at a molecular level the specific interactions for a pair of the ligands and receptors related to the cell adhesion, where the ligands are fixed at the substrates or the AFM probes [8]. Despite their importance for understanding the cell-material adhesion, only a few 
AFM studies have reported the cell adhesion to the artificial materials of the metallic surfaces [9] and the simple surface chemistries [9-16] such as charged hydrophilic groups (e.g., carboxyl and amino), uncharged hydrophilic groups (e.g., hydroxyl and polyethylene glycol), hydrophobic groups (e.g., alkyl and phenyl).

In the earlier studies $[14,16]$, two types of positively charged silica microspheres modified by silane coupling agent of N-trimethylsilylpropyl-N,N,N-trimethylammonium chloride or Nmethylaminopropyltrimethoxysilane were employed. The former microsphere surface had the large positive charge to give the very large adhesion force for melanoma cells [14]. This result is quite understandable on the basis of the electrostatic attraction between the positively charged microsphere surface and the cell surface that is often negatively charged at a neutral $\mathrm{pH}$. On the other hand, the latter had the small positive charge and gave the adhesion force smaller than the carboxyl-modified polystyrene microsphere [16]. The result is not explained solely by the electrostatic interactions between the microsphere and cell surfaces. In addition, the hydrophobic phenyl groups on the unmodified polystyrene microsphere surface gave the very small affinity for melanoma cells [16]. The aim of the present study is to better understand the cell adhesion to the artificial materials of the simple surface chemistries, especially carboxyl-terminated groups.

In the present study, we performed the AFM measurements of the interaction forces between the single murine B16F10 cells and the single microspheres with the surface chemistry of carboxyl groups or hydrophobic phenyl groups in serum-free culture media. The carboxyl-modified microspheres of different diameters were employed to investigate the effects of the microsphere size on the cell-microsphere adhesion. The cell-microsphere interaction forces were also measured in the culture media containing the free RGD peptides as an integrin inhibitor. On the basis of the AFM results, possible mechanism of cell-microsphere adhesion will be discussed.

\section{Materials and methods}




\subsection{Reagents and colloid microspheres}

The chemical reagents of H-Arg-Gly-Asp-OH (RGD) peptide (Calbiochem, San Diego, CA, USA) were purchased and used as received. Five types of polystyrene (PS) microspheres purchased from Bangs Laboratories (Fishers, IN, USA) are listed in Table 1: the unmodified PS microspheres of diameter $2 R=7.33 \mu \mathrm{m}$; and the carboxyl-modified PS microspheres of $2 R=3.09,3.56,6.90$, and 9.95 $\mu \mathrm{m}$, where the number density of carboxyl groups, $n_{\mathrm{COOH}}$, ranged from 0.35 to 2.99 groups $/ \mathrm{nm}^{2}$. Hereafter, the former are referred to as bare/PS microspheres and the latter are called as the COOH/PS microspheres. All water used in the experiments was purified using an Autopure system (WD500; Yamato Scientific, Tokyo, Japan) to give a resistance of $18.2 \mathrm{M} \Omega \mathrm{cm}$ and a total organic carbon of less than $50 \mathrm{ppb}$.

\subsection{Cell line}

The murine melanoma cell line (B16F10; kindly provided by Profs. Fukumori and Ichikawa of Kobe Gakuin University, Kobe, Japan) was cultured in a complete medium composed of an MEM medium (05900, Eagle's minimum essential medium with kanamycin, without L-glutamine or sodium bicarbonate; Nissui Pharmaceutical, Tokyo, Japan), L-glutamine (Nacalai Tesque, Kyoto, Japan) and 10-\% fetal bovine serum (FBS; JRH Biosciences, Lenexa, KS, USA); additionally, sodium bicarbonate (Nacalai Tesque, Kyoto, Japan) was used to adjust the $\mathrm{pH}$ to 7.4. Every component of the media was properly autoclaved or sterile-filtered and the FBS was heat-inactivated, before mixing all of them. The anchorage-dependent cells were stationarily cultivated in a $75-\mathrm{cm}^{2}$ flask $(3110-075$; IWAKI, Tokyo, Japan) containing a 10-mL complete medium, and the flask was stored in an incubator, inside which a moist atmosphere of $5.0-\% \quad \mathrm{CO}_{2}$ was maintained at temperature of $37.0^{\circ} \mathrm{C}$. This ensured that the complete medium exhibited the physiological $\mathrm{pH}$ of 7.4. The complete medium was changed every 2 
days. The cells were subcultured every 4 days, when they formed a subconfluent monolayer of the surface density $0.7 \times 10^{5}$ cells $/ \mathrm{cm}^{2}$ : It is noted that a confluent monolayer of the B16F10 cells gave $0.8 \times 10^{5}$ cells $/ \mathrm{cm}^{2}$. For subculture, the cells were first rinsed with $10 \mathrm{~mL}$ of Dulbecco's phosphatebuffered saline without calcium or magnesium (DPBS, 21600; GIBCO, Grand Island, NY, USA) after removing the complete medium; subsequently, the cells were separated from the base of the flask by trypsinization with a 1-mL DPBS solution of $0.25-\%$ trypsin and 0.02-\% EDTA. A fresh 9-mL complete medium was then added into the $75-\mathrm{cm}^{2}$ flask, giving a $10-\mathrm{mL}$ cell suspension of $5 \times 10^{5}$ cells $/ \mathrm{mL}$. A small amount $(0.25 \mathrm{~mL})$ of this cell suspension was added into a fresh $75-\mathrm{cm}^{2}$ flask including a fresh 10-mL complete medium, giving a cell concentration of $2 \times 10^{3}$ cells $/ \mathrm{cm}^{2}$.

\subsection{Colloid probes}

An AFM probe (Model NP; Veeco Instruments, Santa Barbara, CA, USA), which has a V-shaped, $200-\mu \mathrm{m}$ long cantilever with a spring constant of $0.06 \mathrm{~N} / \mathrm{m}$ and with an $\mathrm{Si}_{3} \mathrm{~N}_{4}$ pyramidal tip on its end, was used. As the PS microspheres were dispersed in water, the water was removed by heating $3 \mu \mathrm{L}$ of the microsphere suspensions in a dry oven at $35^{\circ} \mathrm{C}$ for $15 \mathrm{~min}$. A single microsphere was then attached to the end of the cantilever with a very small amount of thermoplastic epoxy resin (Grade 1004; Japan Epoxy Resins, Tokyo, Japan), using a silicone rubber heater (5099-01; Sogo Laboratory Glass Works, Kyoto, Japan) and an XYZT micromanipulator system (MMO-220B, MMO-202ND, and MMN-1; NARISHIGE, Tokyo, Japan) mounted on a light microscope (BX51; Olympus, Tokyo, Japan). For the smaller $\mathrm{COOH} / \mathrm{PS}$ microspheres of 3.09 - and $3.56-\mu \mathrm{m}$ diameters, an additional microsphere was attached to the free side of the glued microsphere so that the tip of the cantilever never touched the cell samples during the force measurements.

\subsection{Cell samples}


To prepare the B16F10 cell samples for AFM measurements, we used a cell suspension of $5 \times 10^{5}$ cells/mL, which was obtained by subculture procedure mentioned in Section 2.2. Proper amounts of this cell suspension and the complete medium were filled in fresh $\phi 35-\mathrm{mm}$ polystyrene dishes (3000-035; IWAKI, Tokyo, Japan) to satisfy a liquid surface height of $2 \mathrm{~mm}$ and different cell concentrations of $1 \times 10^{5}, 3 \times 10^{5}$, and $5 \times 10^{5}$ cells/mL. After 1-day incubation, all the $\phi 35-\mathrm{mm}$ dishes were checked by a light microscope; consequently, only the culture dishes presenting the confluent monolayer cells were selected for AFM measurements. The selected culture dishes were rinsed with $1 \mathrm{~mL}$ of DPBS after removing the complete medium therein, and filled with $2.5 \mathrm{~mL}$ of an L-15 culture medium (11415-064, Leibovitz's L-15 medium with L-glutamine; GIBCO, Grand Island, NY, USA) so that the pH of the solution therein was maintained at 7.4 even in the outside environment for several hours. In several cases summarized in Table 1, the L-15 solution containing the free RGD peptides as an integrin inhibitor was used, where the RGD concentration equaled $C_{\mathrm{RGD}}=0.1,0.5$, or $1.0 \mathrm{mg} / \mathrm{mL}$. FBS was never added to the L-15 solution for AFM measurements, eliminating the effects of serum proteins on the experimental results.

\subsection{Optical lever method of AFM}

The probe-sample force applied by an AFM is calculated using Hooke's law, $F=k \Delta z$, where $k$ and $\Delta z$ are the spring constant and the vertical deflection of an AFM cantilever, respectively. Thanks to the optical lever method, $\Delta z$ is determined by $\Delta z=S^{-1} \Delta V$, where $\Delta V$ is the total change in the output signal of the laser beam reflected off the back of the cantilever onto a 4-segment photodiode. The optical lever sensitivity, $S$, is defined as the value of the slope in the constant compliance region of a force-displacement curve, that is, the output signal (V) as a function of a Z-piezo displacement $(\mu \mathrm{m})$.

\subsection{Force measurements by AFM}


An MFP-3D-SA AFM (Asylum Research, Santa Barbara, CA, USA) was used to measure the interaction forces between a living cell and a colloid probe in the L-15 solution at room temperature (25 $\pm 2{ }^{\circ} \mathrm{C}$ ), as shown in Fig. 1 . The cantilever with the colloid probe was fixed on the AFM head (the Zscanner). In prior to the cellular force measurement, the optical lever sensitivity, $S$, was determined using a clean mica sheet which was sank on a fresh $\phi 35-\mathrm{mm}$ dish containing water, whereby the surface cleanliness of the colloid probe was checked at the same time. In replacement of this dish, the prepared cell culture dish was then placed on the AFM base (the XY-scanner equipped with the manual XYtranslation stages), below which the built-in light microscope was positioned; as shown in Fig. 1, this enabled us not only to locate the colloid probe over the nucleus of a living cell, but also to monitor the cell during the force measurement. Because the living anchorage-dependent cells during interphase adhered to the dish surface and flatten or spread out thereon, they could be easily distinguished from the mitosis-phase cells and the dead cells, which evidently rounded up to exhibit a spherical shape and were much more loosely attached to the surface [5]. After more than $20 \mathrm{~min}$ of waiting, the AFM measurement was started using the colloid probe and the cells in the culture dish.

In measurement of a compression force curve (see Fig. 2a and b), the colloid probe was brought in contact with the cell of interest at a speed of $1.0 \mu \mathrm{m} / \mathrm{s}$ and a minimum indentation depth of about $1 \mu \mathrm{m}$ required for the probe to reach the cell surface and to give a compliance region. This Z-scan speed was confirmed to be low enough to reduce or eliminate the hydrodynamic effects in the compression/decompression force curves, by comparison among the force curves obtained using higher and lower scan speeds. Once the indentation depth reached the typical values of $d=1.0 \pm 0.5 \mu \mathrm{m}$, resulting in the loading (or pushing) forces of $0.35 \pm 0.2 \mathrm{nN}$, the colloid probe was then allowed to reside on the cell surface for 1 or $5 \mathrm{~min}$, during which time the cell did not migrate but deformed due to the contact with the probe. The contact (or residence) time of $t_{\mathrm{c}}=5 \mathrm{~min}$ was used, unless specified otherwise. This sufficiently long contact time was allowed us to reduce or eliminate viscoelastic effects in the decompression force curves that may have been caused by the deformation of the cell induced by the approach of the colloid probe to the viscoelastic cell. After the contact time, the probe was moved 
away from the cell surface at a speed of $1.0 \mu \mathrm{m} / \mathrm{s}$ (see Fig. $2 \mathrm{c}$ and $\mathrm{d}$ ), which was low enough to avoid large complications from the hydrodynamic drag acting on the colloid probe. In the case of strong adhesions between the cell and the probe, they did not always separate completely after the force cycle of compression, residence, and decompression. For this reason, the probe was moved to another place after the force cycle, and then immediately returned to its original position, in order to break any remaining bonds between the probe and cell; thereafter, another compression force curve was then collected, the baseline of which was used to define the zero force position for the decompression force curve [12-16]. Next, the cell culture dish was moved using the manual XY-translation stages of the AFM base and the next force cycle was then started over the nucleus of another cell. By repeating this procedure, typically $10-15$ force curves were obtained using a pair of the colloid probe and cell culture dish. The force curves of every probe type under each condition of the contact time $t_{\mathrm{c}}$ and the RGD concentration $C_{\mathrm{RGD}}$ were measured at the position over the nucleus of 15-102 different cells, as summarized in Table 1.

\subsection{Zeta potentials of microspheres}

The zeta potential was obtained by electrophoresis at $25{ }^{\circ} \mathrm{C}$ using Zetasizer Nano ZS (Malvern Instruments, Worcestershire, UK), where the velocity of the dispersion in an electrical field was measured. Every sample was diluted and placed in a Universal Dip Cell (ZEN1002; Malvern Instruments). The surface charge of the microspheres was calculated from the mean electrophoretic mobility using Smoluchowski’s equation. The viscosity and dielectric constant of media (pure water and L-15 with/without free RGD peptides) were used as calculation parameters. L-15 culture medium with no phenol red (21083-027; GIBCO) was used. Every sample was measured in triplicate to quintuplicate.

\subsection{Scanning electron microscopy (SEM)}


The B16F10 cells were grown on 9-mm×9-mm coverslips (Matsunami, Osaka, Japan) being sank into the $\phi 35-\mathrm{mm}$ polystyrene dishes, where the cells suspended in the complete medium at $2 \times 10^{4}$ cells $/ \mathrm{mL}$ were seeded. Before use, the coverslips were sterilized in ethanol overnight, washed thoroughly in water, and dried in air inside a bio-clean bench. After 1-day incubation, the dishes with the coverslips were rinsed with $2 \mathrm{~mL}$ of DPBS. For subsequent SEM observation, the samples were fixed in 4-\% paraformaldehyde, 0.1-mol/L phosphate buffer solution, pH 7.3 (Nacalai Tesque, Kyoto, Japan) for 30 min at room temperature, and rinsed three times in $0.1-\mathrm{mol} / \mathrm{L}$ phosphate buffer solution, $\mathrm{pH} 7.4$ for every $10 \mathrm{~min}$. The samples were post-fixed with $1-\% \mathrm{OsO}_{4}$ in $0.075-\mathrm{mol} / \mathrm{L}$ phosphate buffer solution for $30 \mathrm{~min}$ at $4{ }^{\circ} \mathrm{C}$, thoroughly rinsed in water, dehydrated in an ethanol series $(70,80,90,99.5,99.5 \%)$ for every $10 \mathrm{~min}$ at room temperature, and dehydrated twice in t-butyl alcohol for every $15 \min$ at $40{ }^{\circ} \mathrm{C}$, followed by being frozen in a small amount of t-butyl alcohol at $4{ }^{\circ} \mathrm{C}$ and freeze-dried using VFD-21S (Vacuum Device, Ibaragi, Japan). Finally, the samples were sputtered with a conductive layer of 5-nm thickness gold using an Emitech K575XD (Quorum Technologies, Ashford, UK) and imaged using a Keyence VE-8800 (Osaka, Japan).

\subsection{Data analysis}

The force-displacement curves were analyzed using IGOR Pro software, with which the MFP-3D-SA AFM system was equipped. The distribution of the adhesion forces under the same experimental condition will be depicted as a box plot with their six-number summaries: the 0.1-fractile, first quartile, median (second quartile), third quartile, and 0.9-fractile as well as the mean. The significance of the differences among multiple independent setups was tested by the Mann-Whitney U-test or the Kruskal-Wallis test with the Steel-Dwass test, using Microsoft Excel 2003 software and its add-in of Ekuseru-Toukei 2010 (Social Survey Research Information, Tokyo, Japan). 


\section{Results and discussion}

\subsection{Morphology of apical surface of cells}

SEM was used to illustrate the surface of the B16F10 cells and the micrographs are shown in Fig. 3. The apical surface of the cells appeared to be rather rough and exhibited a dense lawn of microvilli and microridges. On the other hand, the dynamic mode AFM gave the images of the smooth apical surface of the B16F10 cells $[12,13]$ and failed to visualize these detailed structures of the cellular surface. This is mainly because the colloid probes with a microsphere of $6.84-\mu \mathrm{m}$ diameter, other than the probes with a sharp tip, were employed for AFM imaging $[12,13]$. The complicated structure of the cell surface explains one of the reasons why molecular-level interpretation of the force-displacement curves is very difficult, as will be mentioned in Section 3.2.

\subsection{Force-displacement curves}

Figure 4 displays typical force-displacement curves during compression and decompression measured between a living B16F10 cell and a microsphere of approximately the same diameter $(\sim 7 \mu \mathrm{m})$ but of different surface chemistries in culture media without free RGD peptide. The force curves for the $\mathrm{COOH} / \mathrm{PS}$ and the bare/PS microspheres had similar features, as described in the followings.

The compression curve for every microsphere displayed zero force at the distances longer than $\sim 1 \mu \mathrm{m}$, at which a repulsive force was detected. This repulsion is not electrostatic in origin, because all the cellmicrosphere interaction forces were measured in the L-15 culture media of a high ionic strength (>140 $\mathrm{mM}$ ) [12]. It should be noted that electrostatic forces between two charged surfaces become weaker with increasing the concentration of salt in the intervening medium, where the counterions shield the charges on the surfaces [17]. Instead, this repulsion at the distances shorter than $\sim 1 \mu \mathrm{m}$ probably originated from both steric stabilization forces and viscoelastic forces (see also Figs. $2 b$ and 3 ); the 
former are caused by the compression of a hydrated layer of long-chain polymer molecules (proteins and carbohydrates) on the cell surface, while the latter result from the viscoelastic property of a cell [18]. During the contact time of $t_{\mathrm{c}}=5 \mathrm{~min}$, no significant change was observed in the force-displacement curve and the microsphere was not likely to enter the B16F10 cell. Similar results were obtained for the $\mathrm{COOH} / \mathrm{PS}$ microspheres of different diameters of $3.09,3.56$, and $9.95 \mu \mathrm{m}$. These results suggest that the B16F10 cells never uptake the microspheres of 3-10 $\mu \mathrm{m}$ diameter during the time period of $5 \mathrm{~min}$.

A force curve during decompression after compression and residence is the result of detachment of a microsphere from the apical surface of a cell (see also Fig. 2c). The decompression force curve for every microsphere showed an initial, large de-adhesion peak followed by several small steps of 20-40 $\mathrm{pN}$, indicating that two types of the microspheres employed in the present study adhered onto the apical surface of the B16F10 cell shown in Fig. 3. The small steps are attributable to the breaking of the multiple bonds formed at different locations of close contact between the cell and microsphere surfaces. Such small steps are classified into two types: short "J-steps" in short-distance region and long "Tsteps" in long-distance region [6]. After a subset of several J-steps was observed, a few T-steps appeared to exhibit the force plateaus extending over several micrometers. This behavior of the T-steps could be explained by membrane tethers of several micrometers long, where the cytoskeleton and membrane deform upon pulling in the presence of punctuated binding between the cell and microsphere surfaces [19], as observed by Sun et al. [20]. Similar results of the decompression force curves were obtained for the COOH/PS microspheres of different diameters of 3.09, 3.56, and $9.95 \mu \mathrm{m}$. It should be noted that the decompression force curves for $t_{\mathrm{c}}=1 \mathrm{~min}$ or $C_{\mathrm{RGD}}>0$ (not shown) were qualitatively similar to those of Fig. 4 for $t_{\mathrm{c}}=5 \mathrm{~min}$ and $C_{\mathrm{RGD}}=0$.

Still, it is challenging to interpret the decompression force curve between the cell and material surfaces from a molecular point of view, because a large number of known/unknown adhesion processes can occur simultaneously [8] and the apical surface of cells often exhibits a rather rough and complex structure as shown in Fig. 3. For this reason, the magnitude of the attractive force at the initial deadhesion peak $\left(F_{\text {adh }}\right)$ has been used as a measure of the overall cell-microsphere adhesion force in the 
present study. It is noted that $F_{\text {adh }}$ is the force required for detaching the microsphere from the cell; the larger value of $F_{\text {adh }}$ would indicate the stronger adhesion $[8,21]$.

\subsection{Effects of contact time on adhesion forces}

The distributions of adhesion force $F_{\text {adh }}$ between a living B16F10 cell and a COOH/PS microsphere of 6.90- $\mu \mathrm{m}$ diameter for the contact time of $t_{\mathrm{c}}=1$ and $5 \mathrm{~min}$ are depicted as the box plots in Fig. 5. The distribution of $F_{\text {adh }}$ for $t_{\mathrm{c}}=5$ min was broader and exhibited the larger values, compared with that for $t_{\mathrm{c}}$ $=1 \mathrm{~min}$. The median of $F_{\mathrm{adh}}$ for $t_{\mathrm{c}}=5 \mathrm{~min}(1.16 \mathrm{nN})$ was about three times larger than that for $t_{\mathrm{c}}=1 \mathrm{~min}$ $(0.40 \mathrm{nN})$, demonstrating that the adhesion becomes strong with increasing the contact time $[6,7,9,12$, 21]. The increase in adhesion force after 5-min contact mainly results from the increase in net area of close contact between the smooth, hard surface of a microsphere and the rough, soft surface of a B16F10 cell (see Fig. 3) with time. Thus, the contact time as well as the loading force (or the indentation depth) are critical parameters for cell adhesion studies, because (i) the number of bonds formed and the degree of their clustering and (ii) the net area of close contact between the cell and material surfaces will differ with these two parameters [6].

\subsection{Effects of microsphere diameter and surface density of carboxyl groups on adhesion forces}

Figure 6 shows the distributions of adhesion force $F_{\text {adh }}$ between a living B16F10 cell and a COOH/PS microsphere of diameter $2 R=3.09,3.56,6.90$, and $9.95 \mu \mathrm{m}$, which had the number density of carboxyl groups, $n_{\mathrm{COOH}}=2.99,0.35,0.87$, and 1.06 groups $/ \mathrm{nm}^{2}$, respectively. Additionally, the distributions of the adhesion force normalized by the contact area, $F_{\text {adh }} / S_{0}$, are shown in Fig. 6. One can estimate the contact area, $S_{0}$, from the shape of the compression force curve using the Hertz contact model, where a spherical indenter of radius $R$ is considered to be pushed onto a smooth, homogeneous, semi-infinite elastic solid $[22,23]$. The depth of indentation, $d$, was calculated from the compression force curve as 
the difference between the Z-piezo displacement and the deflection of cantilever after the colloid probe touched the sample surface [24]. The contact area, $S_{0}$, was calculated from the maximum value of $d$ at the end of indentation, according to the following formulae [10]:

$$
S_{0}=2 p R^{2} \cdot{ }_{0}^{q_{0}} \sin q \mathrm{~d} q=2 p R^{2}\left(1-\cos q_{0}\right)
$$

where $\theta_{0}$ is defined as

$$
\sin q_{0}=\sqrt{\frac{d}{R}}
$$

It should be noted that $S_{0}$ is a measure of the contact area of the microsphere surface facing onto the cell surface and is larger than the net area of close contact between the smooth, hard surface of a microsphere and the rough, soft surface of a B16F10 cell. The close-contact area increases with contact time, as pointed out in Section 3.3, and should eventually reach to $S_{0}$ if the close contact between the cell and microsphere surfaces is completely established in the contact area.

First, let us make a comparison between the results in Fig. 6 for the $3.09-\mu \mathrm{m}$ microspheres of $n_{\mathrm{COOH}}=$ 2.99 groups $/ \mathrm{nm}^{2}$ and those for the $3.56-\mu \mathrm{m}$ microspheres of $n_{\mathrm{COOH}}=0.35$ groups $/ \mathrm{nm}^{2}$, where the difference in diameter between these two types of the microspheres was negligible, but the differences in $n_{\mathrm{COOH}}$ and in zeta potential were significant (see Table 1). The distributions of $F_{\text {adh }}$ and $F_{\text {adh }} / S_{0}$ for the former were almost the same as those for the latter with statistical accuracy, where $P=0.99$ for $F_{\text {adh }}$ and $F_{\text {adh }} / S_{0}$. Supposed that the adhesion force is given by a sum of individual bonds of $20 \mathrm{pN}$ (see Section 3.2), the number of interaction bonds at work between the cell and microsphere surfaces is estimated as 12.1 and 10.7 bonds $/ \mu \mathrm{m}^{2}$ (i.e., $1.21 \times 10^{-5}$ and $1.07 \times 10^{-5}$ bonds $/ \mathrm{nm}^{2}$ ) for the COOH/PS microspheres of $3.09-\mu \mathrm{m}$ and $3.56-\mu \mathrm{m}$ diameters, respectively, which are about five orders of magnitude smaller than the corresponding values of $n_{\mathrm{COOH}}=2.99$ and 0.35 groups $/ \mathrm{nm}^{2}$. These results indicate that within the range of $n_{\mathrm{COOH}}=0.35-2.99$ groups $/ \mathrm{nm}^{2}$, the surface density of carboxyl groups as well as the zeta potential hardly affected the adhesion force. Because four types of the COOH/PS microspheres employed had $n_{\mathrm{COOH}}$ in this range as listed in Table 1 , the difference in adhesion force is dominantly 
attributable to the difference in microsphere diameter. Henceforth, we will discuss Fig. 6 in term of the difference in microsphere diameter.

As shown in Fig. 6a, $F_{\text {adh }}$ in the range of $2 R=3.09-9.95 \mu \mathrm{m}$ seemed to exhibit a maximum at $2 R=$ $6.90 \mu \mathrm{m}$ under the same conditions of contact time $\left(t_{\mathrm{c}}=5 \mathrm{~min}\right)$ and indentation depth $(d \sim 1.0 \mu \mathrm{m})$, where the contact area would increase with the microsphere diameter of $2 R$. This result is contrary to common expectation that $F_{\text {adh }}$ should increase with $2 R$. Thus, the cell-microsphere adhesion is influenced by the microsphere diameter, and its dependence on the diameter is far from straightforward because of the complications resulting from the active cellular response to the external mechanical forces exerted by the microsphere. The cellular response includes the viscoelastic stress-relaxation followed by tension recovery [25], which should depend on the size of indenter and the depth of indentation and is still open question. It is worth noting that one should use the microspheres of the same diameter to investigate by AFM how the surface chemistry of the microspheres affects the cell-microsphere adhesion.

\subsection{Effects of surface chemistry of microsphere and free RGD peptides on adhesion forces}

Figure 7 displays the distributions of adhesion force $F_{\text {adh }}$ between a living B16F10 cell and a microsphere of $6.90-\mu \mathrm{m} \mathrm{COOH} / \mathrm{PS}$ or $7.33-\mu \mathrm{m}$ bare/PS at the RGD concentrations of $C_{\mathrm{RGD}}=0,0.1,0.5$, $1.0 \mathrm{mg} / \mathrm{mL}$. The distribution width for $F_{\text {adh }}$ seen from the interquartile range as well as the whisker range can be thought to depict the variation in the surface properties of individual cells, that is, the cellto-cell difference in the number of sites on the individual cell surface that can bind with the microsphere surface. For the COOH/PS, $F_{\text {adh }}$ decreased with $C_{\mathrm{RGD}}$ and became almost constant at concentrations of $C_{\mathrm{RGD}} \geq 0.5 \mathrm{mg} / \mathrm{mL}$, where the medians of $F_{\text {adh }}$ were about one fifth of those at $C_{\mathrm{RGD}}=0$ and $0.1 \mathrm{mg} / \mathrm{mL}$ and the distribution widths were remarkably reduced. On the other hand, the median and the distribution width of $F_{\text {adh }}$ for the bare/PS remained small regardless of the RGD concentration, compared with that for the $\mathrm{COOH} / \mathrm{PS}$. Because the $\mathrm{COOH} / \mathrm{PS}$ and the bare/PS microspheres in Fig. 7 had approximately the 
same diameter $(\sim 7 \mu \mathrm{m})$, the difference in $F_{\text {adh }}$ between these two types of the microspheres is mainly attributable to the difference in surface chemistries. The surface of the bare/PS microspheres is hydrophobic in essence because of phenyl groups $\left(-\mathrm{C}_{6} \mathrm{H}_{5}\right)$ being the main component of the PS microspheres, whereas a COOH/PS microsphere is considered to be a carboxylic acid functionalized bare/PS microsphere and its surface can be thought of consisting of both carboxyl and phenyl groups.

The malignant melanoma cells, such as B16F10 cells used in the present study, remarkably express several types of adhesion receptors from the integrin family of heterodimers of $\alpha$ and $\beta$ subunits [26]. Many members of the integrin family recognize an RGD motif within their ligands including fibronectin, vitronectin, and many other glycoproteins [27, 28]. Peptides containing ligand-mimetic RGD sequences specifically bind the headpiece of integrin [27] and can effectively block the integrin-ligand interactions [26, 29-32]. However, this is not the case for the considerable decrease of $F_{\text {adh }}$ with $C_{\mathrm{RGD}}$ for the $\mathrm{COOH} / \mathrm{PS}$ shown in Fig. 7, because there is no specific interaction of integrin with COOH motif to the best of our knowledge.

Instead, the result of Fig. 7 indicates that the $\mathrm{COOH}$ groups on the microsphere surface interacted somehow or other with the cell surface via integrins and the nonspecific $\mathrm{COOH}$-integrin interaction was reduced by the presence of free RGD peptides. This postulation would be supported by the facts that the RGD-recognizing integrins have several binding sites for divalent cations such as $\mathrm{Ca}^{2+}$ and exhibit three structures: (i) the bent legs with unliganded-closed headpiece; (ii) the extended legs with unliganded-closed headpiece; and (iii) the extended legs with liganded-open headpiece [27]. It is most likely that the negatively charged $\mathrm{COOH}$ groups on the microsphere surface attractively interacted with these divalent cations bound to the integrin, and that RGD peptides added in the culture medium electrostatically neutralized the divalent cations and bound the headpiece of integrin to induce its structural change from structures (i) and (ii) to structure (iii). These two effects of RGD peptides on integrin would result in decrease of the attraction between the $\mathrm{COOH}$ groups and bound divalent cations, leading to reduction of $F_{\text {adh }}$ between the COOH/PS microsphere and B16F10 cell. It should be noted that this reduction of $F_{\text {adh }}$ is not ascribed to the charge neutralization of the negatively charged $\mathrm{COOH}$ 
groups on the microsphere surface by RGD addition, because the zeta potential of the COOH/PS microsphere in the culture medium remained almost constant $(\approx-16 \mathrm{mV})$ in the range of $C_{\mathrm{RGD}}=0-1.0$ $\mathrm{mg} / \mathrm{mL}$ as shown in Table 1.

As for the bare/PS microspheres, on the other hand, Fig. 7 shows no significant variations of $F_{\text {adh }}$ with $C_{\mathrm{RGD}}$ and the small medians. The results indicate that the bare/PS microsphere surface of hydrophobic nature interacted with the cell surface through van der Waals forces and hydrophobic forces with hydrophobic portions on the cell surface (e.g., the nonpolar amino acids), as pointed out in the earlier study [16].

\section{Conclusions}

In the present study, we performed the AFM measurements of the interaction forces between the single B16F10 cells and the single polystyrene microspheres of different diameters and different surface chemistries in serum-free culture media. It was found that the adhesion force became strong with increasing the contact time, which would result from the increase in net area of close contact between the microsphere and the cell surfaces with time. The carboxyl-modified polystyrene microspheres of different diameters exhibited a maximum at the diameter of $6.90 \mu \mathrm{m}$ in the range of 3.09-9.95 $\mu \mathrm{m}$ under the same conditions of contact time $(=5 \mathrm{~min})$ and indentation depth $(\sim 1.0 \mu \mathrm{m})$, where the contact area would increase with the microsphere diameter. The cell-microsphere adhesion is thus influenced by the microsphere diameter and its dependence on the diameter is far from straightforward, because of the complications resulting from the active cellular response to the external mechanical forces exerted by the microsphere. Also, it was found that the adhesion force for the carboxyl-modified polystyrene microspheres was larger than that for the unmodified hydrophobic polystyrene microspheres, where these microspheres had nearly the same diameters $(\sim 7 \mu \mathrm{m})$. When the free RGD peptides were added into culture media as an integrin inhibitor, the adhesion force for the former microspheres decreased 
with increasing the RGD concentration and then became almost constant at the RGD concentrations larger than $0.5 \mathrm{mg} / \mathrm{mL}$, whereas that for the latter microspheres remained very small regardless of the RGD concentration. These results indicate that carboxyl-modified polystyrene microspheres interacted rather strongly with the cell surfaces, whereas the hydrophobic polystyrene microspheres interacted weakly with the cell surfaces through van der Waals forces and hydrophobic forces.

\section{Acknowledgements}

The authors thank for financial support by the Ministry of Education, Culture, Sports, Science and Technology (MEXT) in Japan (Grants-in-Aid for Scientific Research, No. 18360394/22686072; Strategic Development of Research Infrastructure for Private Universities, No. S0901039), the Japan

Society for the Promotion of Science (JSPS; Core-to-Core Program, No. 18004), the Inamori Foundation, and the Information Center of Particle Technology, Japan. 
Fig. 1. Light microscope image of B16F10 cells and a V-shape cantilever with a glued microsphere (arrow). The full length of the cantilever is $200 \mu \mathrm{m}$. The scale bar is $50 \mu \mathrm{m}$.

Fig. 2. Illustration of four steps in the acquisition of an AFM force measurement: The arrows indicate the direction of cantilever movement.

Fig. 3. (a) Scanning electron micrograph of B16F10 cells and (b) the magnification of its central region.

Fig. 4. Typical force-displacement curves during compression (upper, red colored) and decompression (lower, blue colored) measured between a living B16F10 cell and a microsphere of different surface chemistries: (a) the COOH/PS microsphere of $6.90-\mu \mathrm{m}$ diameter and (b) the bare/PS microsphere of 7.33- $\mu \mathrm{m}$ diameter. The contact time of $t_{\mathrm{c}}=5 \mathrm{~min}$ and the culture media of $C_{\mathrm{RGD}}=0$ were employed.

Fig. 5. The box plots of the distributions of adhesion force $F_{\text {adh }}$ between a living B16F10 cell and a $\mathrm{COOH} / \mathrm{PS}$ microsphere of $6.90-\mu \mathrm{m}$ diameter for the contact time of $t_{\mathrm{c}}=1$ and 5 min in the culture media of $C_{\mathrm{RGD}}=0$, where $P<0.001$.

Fig. 6. (a) The box plots of the distributions of adhesion force $F_{\text {adh }}$ between a living B16F10 cell and a $\mathrm{COOH} / \mathrm{PS}$ microsphere of diameter $2 R=3.09,3.56,6.90$, and $9.95 \mu \mathrm{m}$, which had the number density of carboxyl groups, $n_{\mathrm{COOH}}=2.99,0.35,0.87$, and 1.06 groups $/ \mathrm{nm}^{2}$, respectively. (b) The box plots of the distributions of the adhesion force normalized by the estimated contact area, $F_{\text {adh }} / S_{0} . P<0.001$ for panels a and $\mathrm{b}$. The contact time of $t_{\mathrm{c}}=5 \mathrm{~min}$ and the culture media of $C_{\mathrm{RGD}}=0$ were employed.

Fig. 7. The box plots of the distributions of adhesion force $F_{\text {adh }}$ between a living B16F10 cell and a microsphere of $6.90-\mu \mathrm{m} \mathrm{COOH} / \mathrm{PS}$ or $7.33-\mu \mathrm{m}$ bare/PS at the RGD concentrations of $C_{\mathrm{RGD}}=0,0.1,0.5$, $1.0 \mathrm{mg} / \mathrm{mL}: P<0.001$ and $P=0.018$ for the former and the latter microspheres, respectively. The contact time of $t_{\mathrm{c}}=5$ min was employed. 
Fig. 1

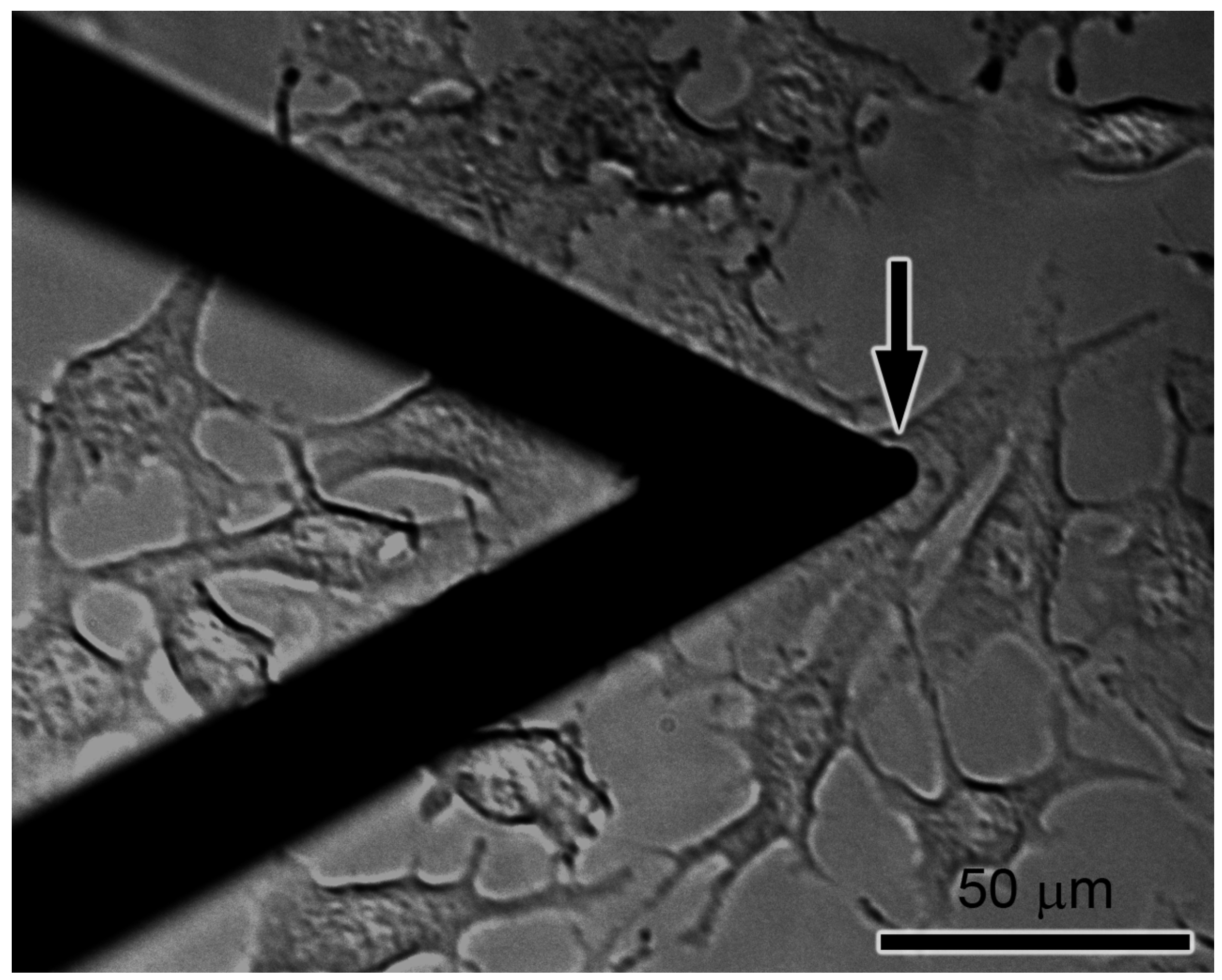


(a) approach

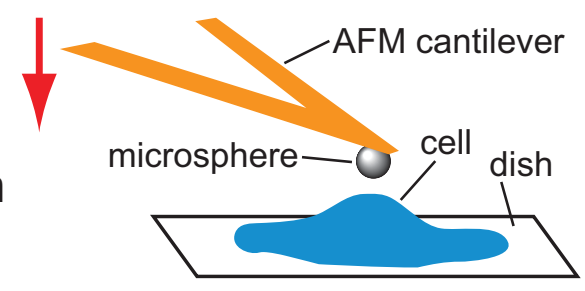

(b) contact

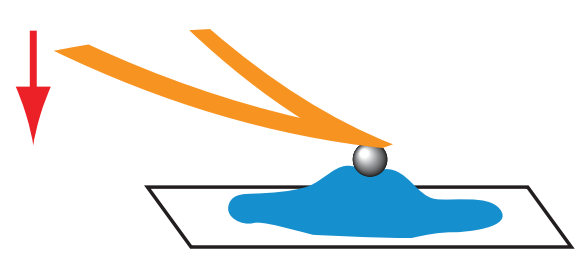

(c) retract

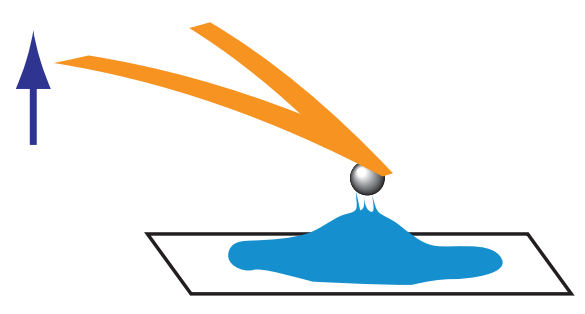

(d) separation

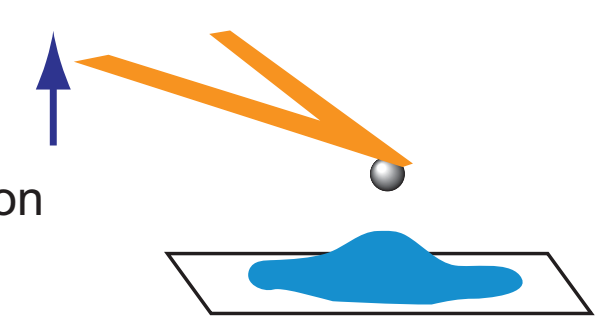

Fig. 2 Shinto et al. 


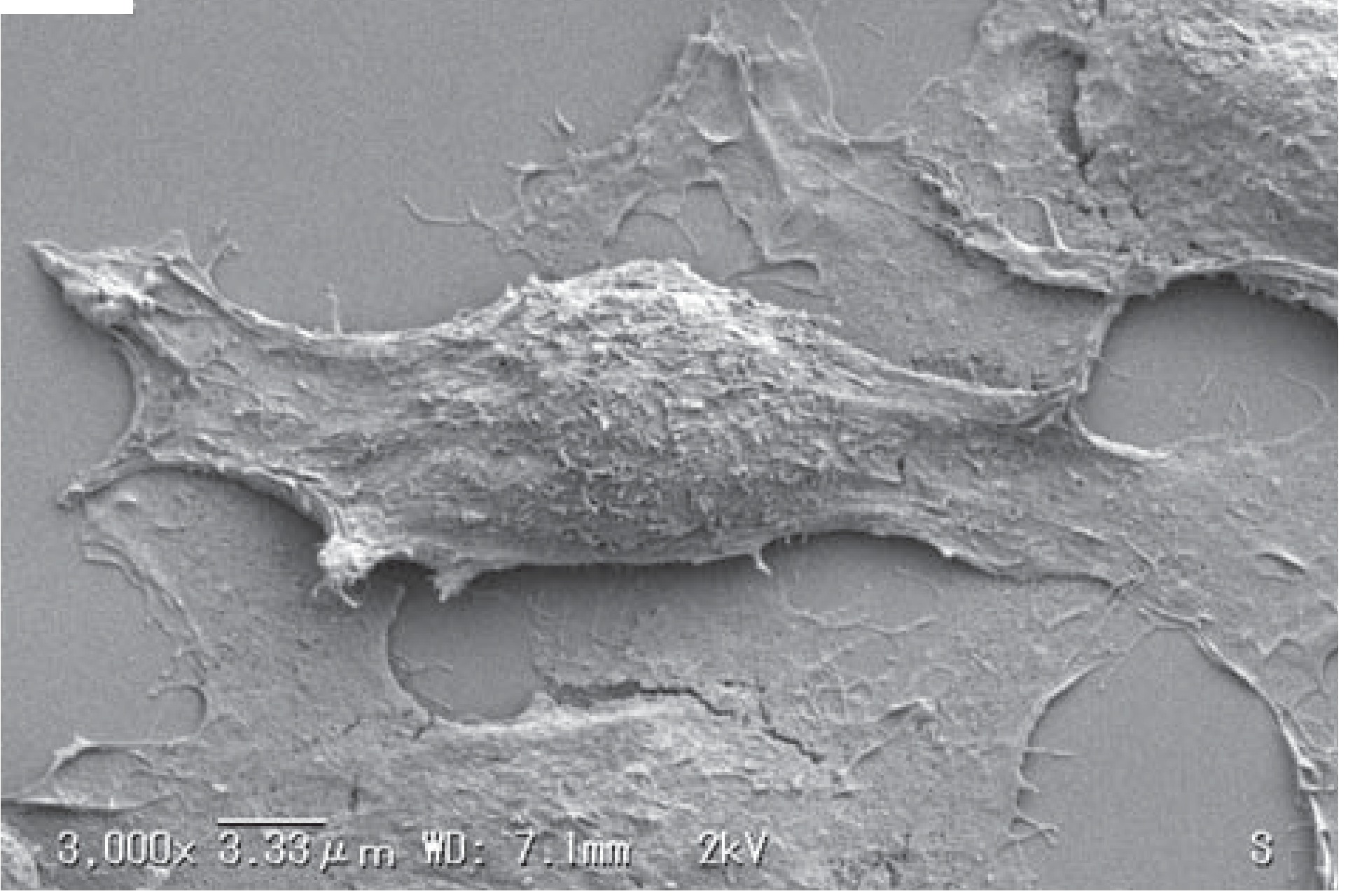
(b) (b)

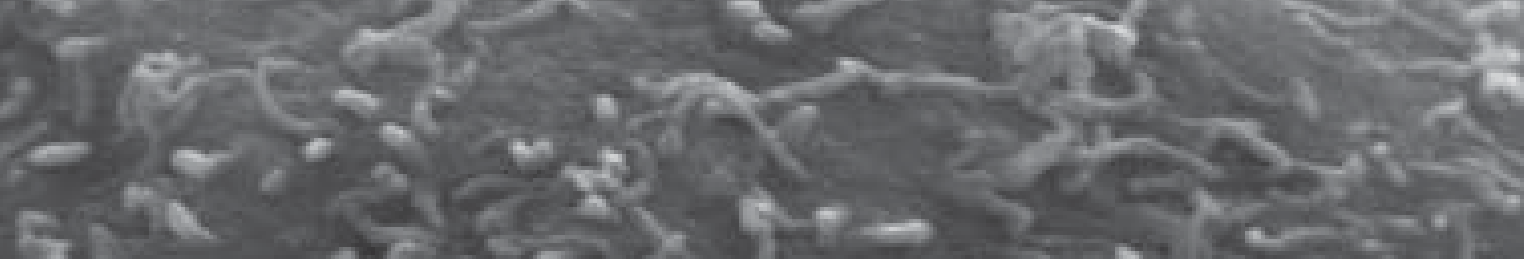

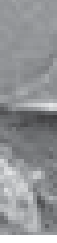

(b)

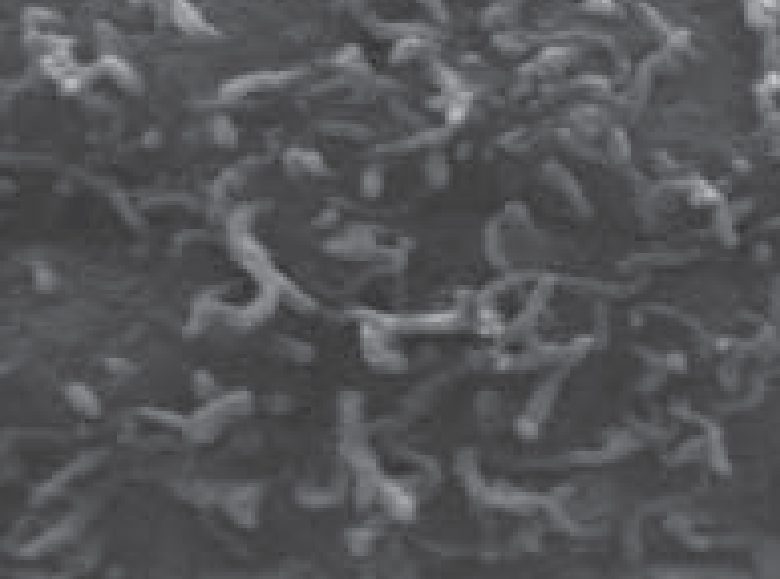



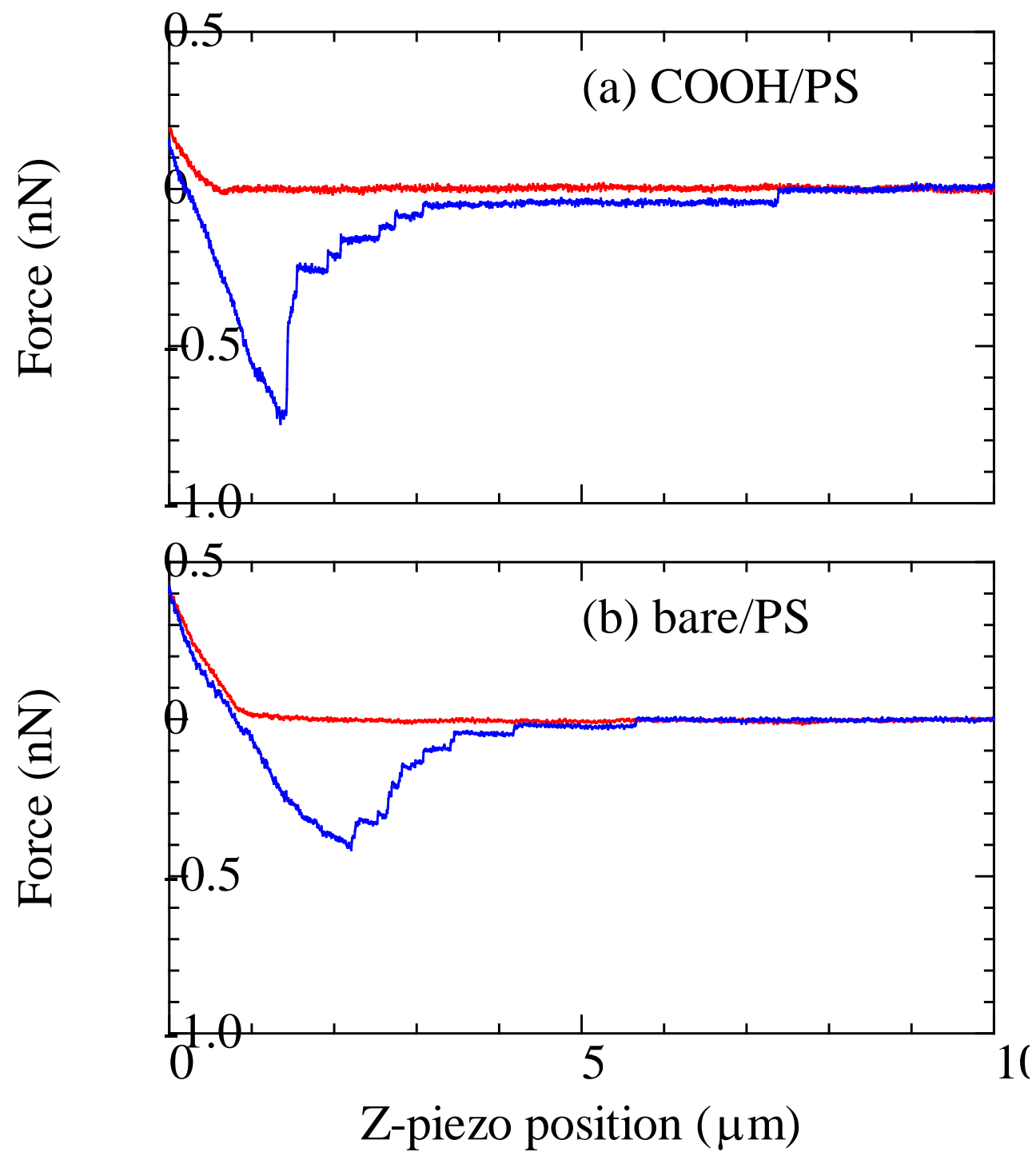

Fig. 4 Shinto et al. 


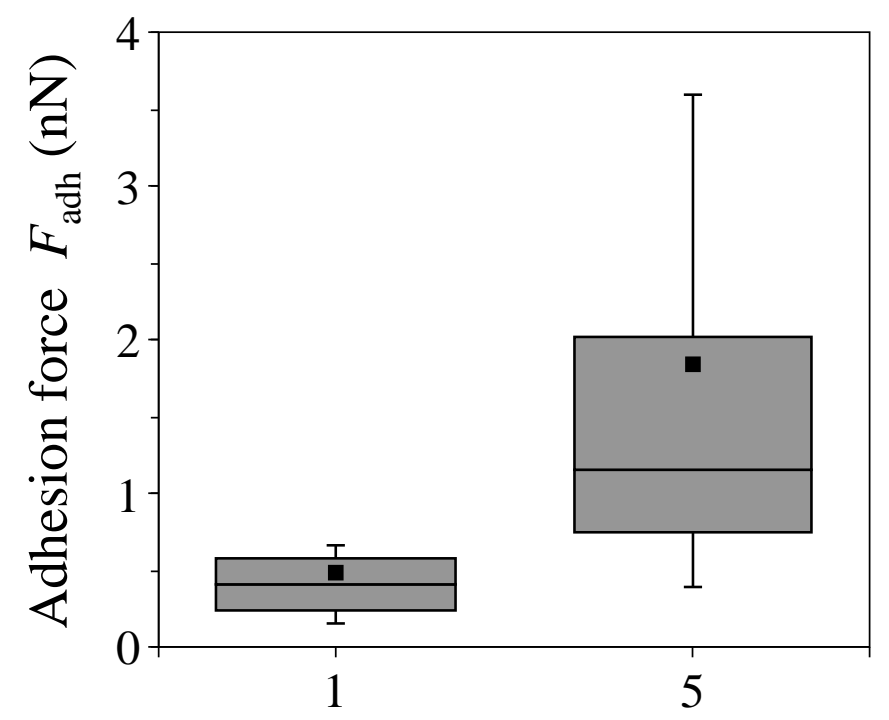

Contact time $t_{\mathrm{c}}(\mathrm{min})$

Fig. 5 Shinto et al. 

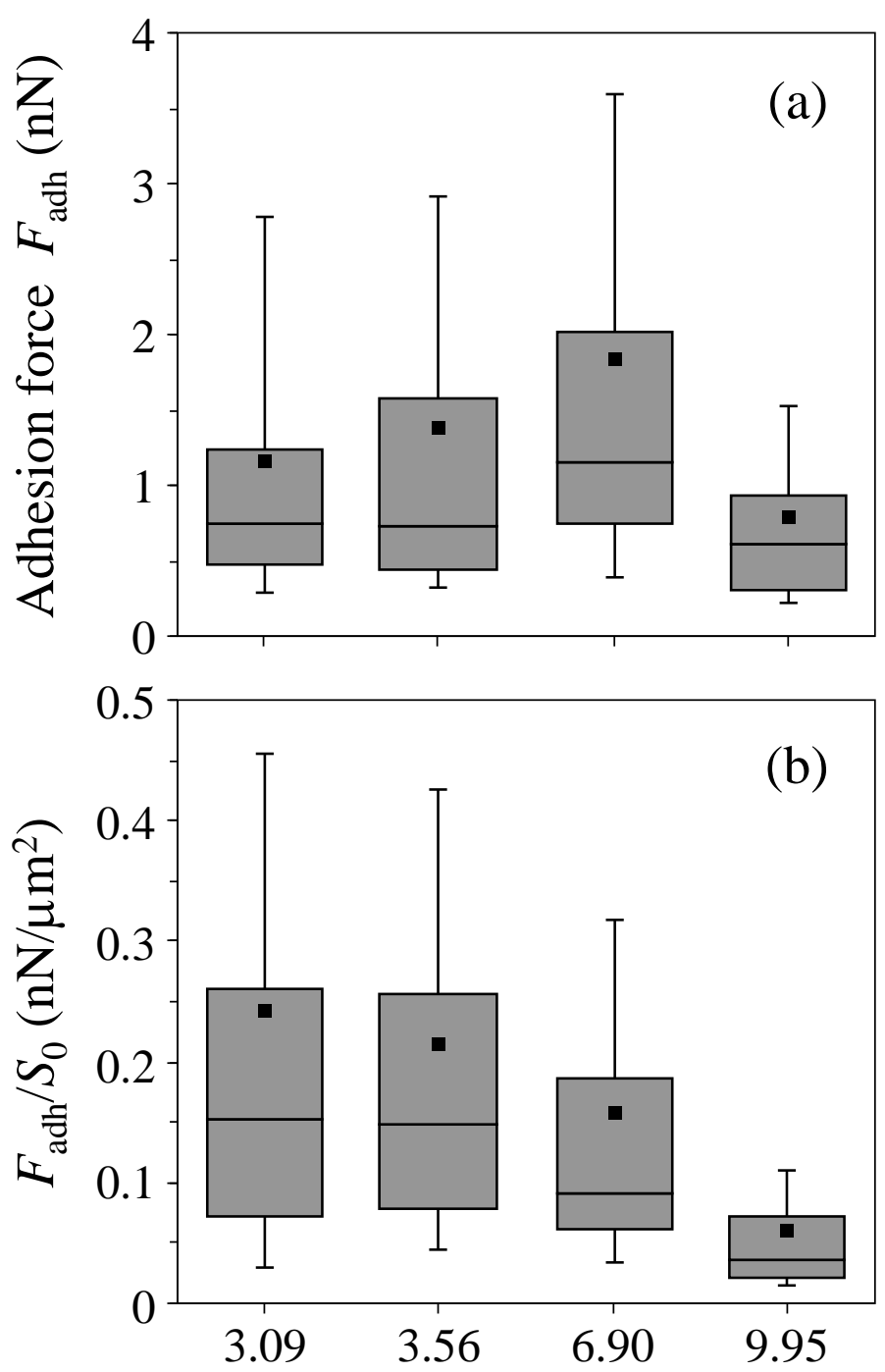

Microsphere diameter $2 R(\mu \mathrm{m})$

Fig. 6 Shinto et al. 


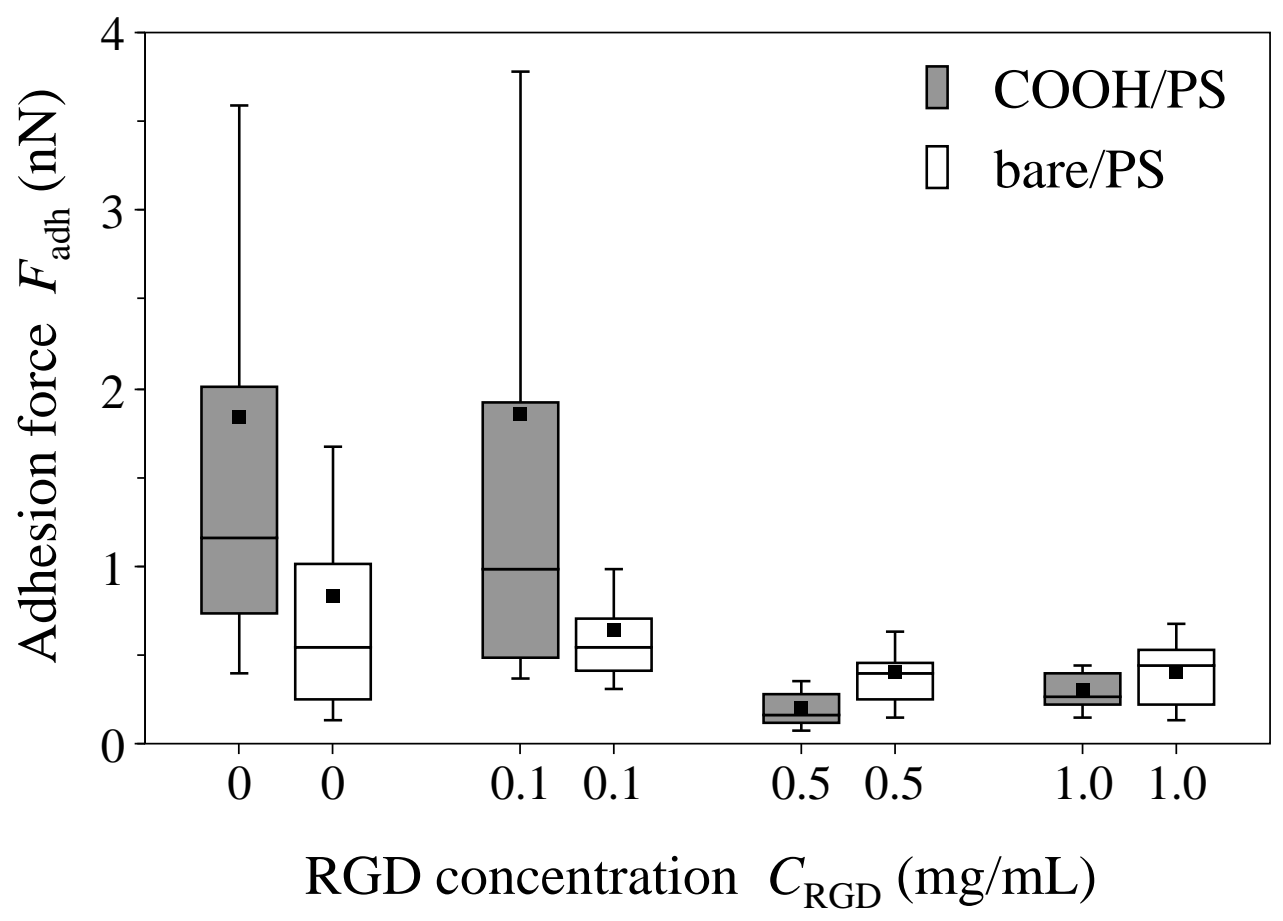

Fig. 7 Shinto et al. 
Table 1

Physicochemical properties of PS microspheres as well as numbers of force measurements and the median of adhesion forces $\left(F_{\mathrm{adh}}\right)$ for different PS microspheres and different concentrations of free RGD peptides dissolved into an L-15 culture medium $\left(C_{\mathrm{RGD}}\right)$ at contact time of $t_{\mathrm{c}}=5 \mathrm{~min}$

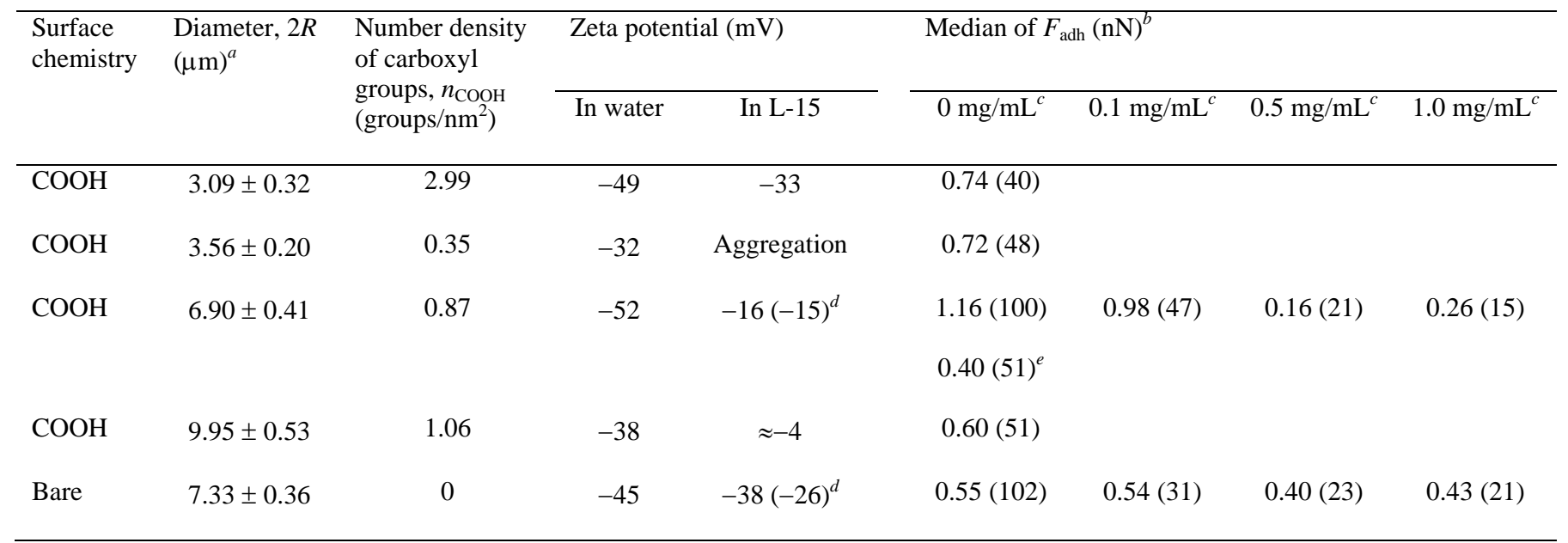

\footnotetext{
${ }^{a}$ The volume mean average diameter with the standard deviation is given.

${ }^{b}$ The value in the parentheses indicates the number of force measurements.

${ }^{c}$ The value of $C_{\mathrm{RGD}}$.

${ }^{d}$ The zeta potential in L-15 medium including $1.0 \mathrm{mg} / \mathrm{mL}$ free RGD peptides.

${ }^{e}$ The values for $t_{\mathrm{c}}=1 \mathrm{~min}$.
} 


\section{References}

[1] M.R. Koller and E.T. Papoutsakis, in: M.A. Hjortso, J.W. Roos (Eds.) Cell Adhesion: Fundamentals and Biotechnological Applications, Marcel Dekker, New York, 1994, Chapter 3.

[2] B. Alberts, A. Johnson, J. Lewis, M. Raff, K. Roberts and P. Walter, Molecular Biology of the Cell, 5th ed., Garland Science, New York, 2007.

[3] C.D. Tidwell, S.I. Ertel, B.D. Ratner, B.J. Tarasevich, S. Atre and D.L. Allara, Langmuir, 13 (1997) 3404-3413.

[4] N. Faucheux, R. Schweiss, K. Lützow, C. Werner and T. Groth, Biomaterials, 25 (2004) 2721-2730.

[5] R.I. Freshney, Culture of Animal Cells: A Manual of Basic Technique and Specialized Applications, 6th ed., Wiley-Blackwell, Hoboken, New Jergey, 2010.

[6] C.M. Franz, A. Taubenberger, P.-H. Puech and D.J. Müller, Sci. STKE, 2007 (2007) pl5.

[7] M. Thie, R. Röspel, W. Dettmann, M. Benoit, M. Ludwig, H.E. Gaub and H.-W. Denker, Human Reproduction, 13 (1998) 3211-3219.

[8] J. Helenius, C.-P. Heisenberg, H.E. Gaub and D.J. Müller, J. Cell. Sci., 121 (2008) 1785-1791.

[9] M. Benoit and H.E. Gaub, Cells Tissues Organs, 172 (2002) 174-189.

[10] H. Kim, H. Arakawa, T. Osada and A. Ikai, Colloids Surf. B: Biointerfaces, 25 (2002) 33-43.

[11] H. Kim, H. Arakawa, T. Osada and A. Ikai, Ultramicroscopy, 97 (2003) 359-363.

[12] C.E. McNamee, N. Pyo, S. Tanaka, I.U. Vakarelski, Y. Kanda and K. Higashitani, Colloids Surf. B: Biointerfaces, 48 (2006) 176-182.

[13] N. Pyo, S. Tanaka, C.E. McNamee, Y. Kanda, Y. Fukumori, H. Ichikawa and K. Higashitani, Colloids Surf. B: Biointerfaces, 53 (2006) 278-287.

[14] C.E. McNamee, N. Pyo and K. Higashitani, Biophys. J., 91 (2006) 1960-1969.

[15] C.E. McNamee, S. Yamamoto and K. Higashitani, Biophys. J., 93 (2007) 324-334.

[16] C.E. McNamee, Y. Aso, S. Yamamoto, Y. Fukumori, H. Ichikawa and K. Higashitani, Pharm. Res., 24 (2007) 2370-2380.

[17] J.N. Israelachvili, Intermolecular and Surface Forces, 3rd ed., Academic Press, San Diego, 2010.

[18] S. Iyer, R.M. Gaikwad, V. Subba-Rao, C.D. Woodworth and I. Sokolov, Nat. Nanotechnol., 4 (2009) 389-393.

[19] E.A. Evans and D.A. Calderwood, Science, 316 (2007) 1148-1153.

[20] M. Sun, J.S. Graham, B. Hegedus, F. Marga, Y. Zhang, G. Forgacs and M. Grandbois, Biophys. J., 89 (2005) 4320-4329.

[21] A. Taubenberger, D.A. Cisneros, J. Friedrichs, P.-H. Puech, D.J. Müller and C.M. Franz, Mol. Biol. Cell, 18 (2007) 1634-1644. 
[22] H. Hertz, Journal für die Reine und Angewandte Mathematik, 92 (1881) 156-171.

[23] I.N. Sneddon, Int. J. Engng. Sci., 3 (1965) 47-57.

[24] G.T. Charras, P.P. Lehenkari and M.A. Horton, Ultramicroscopy, 86 (2001) 85-95.

[25] T. Watanabe-Nakayama, S. Machida, I. Harada, H. Sekiguchi, R. Afrin and A. Ikai, Biophys. J., 100 (2011) 564-572.

[26] R.H. Kramer, M. Vu, Y.-F. Cheng and D.M. Ramos, Cancer Metastasis Rev., 10 (1991) 49-59.

[27] B.-H. Luo, C.V. Carman and T.A. Springer, Annual Review of Immunology, 25 (2007) 619-647.

[28] J. Takagi, K. Strokovich, T.A. Springer and T. Walz, EMBO J, 22 (2003) 4607-4615.

[29] H. Oharazawa, N. Ibaraki, K. Ohara and V.N. Reddy, Ophthalmic Res., 37 (2005) 191-196.

[30] Z. Sun, L.A. Martinez-Lemus, A. Trache, J.P. Trzeciakowski, G.E. Davis, U. Pohl and G.A. Meininger, Am. J. Phys. Heart Circulatory Physiol., 289 (2005) H2526-2535.

[31] P.-H. Puech, K. Poole, D. Knebel and D.J. Müller, Ultramicroscopy, 106 (2006) 637-644.

[32] J. Kirkham, I. Andreev, C. Robinson, S.J. Brookes, R.C. Shore and D.A. Smith, Eur. J. Oral Sci., 114 (2006) 219-224. 